\title{
Contribution of components of Green Supply Chain Migration strategies in Green Supply Chain Performance measurement-A Pilot Empirical Study of the Indian Automobile Manufacturing Sector
}

\author{
Mohd. Asif Gandhi ${ }^{1}$ \\ ${ }^{I}$ Department of Mechanical Engineering, Anjumain-I-Islam's Kalsekar Technical Campus, School of \\ Engineering and Technology, Mumbai University, India
}

\begin{abstract}
This paper is one of the several extensions of the research works done by [5]. Green Supply Chain Practices have been known to have an impact on Green Supply Chain Performance [5].This paper tests empirically through a pilot study of the Indian Automobile Manufacturing Sector, the contribution of the five variables constituting the construct Green Supply Chain Migration strategies in Green Supply Chain Performance measurement. Also the paper establishes the reliability of the questionnaire instrument developed previously for measuring the construct Green Supply Chain Migration strategies and also for measuring the five variables that constitute the construct Green Supply Chain Migration strategies. Further the paper establishes the correlation among these five variables. Finally this paper conducts Confirmatory Factor Analysis (CFA) to arrive at a single factor (linear combination of five variables constituting the construct Green Supply Chain Migration strategies) to aid in measuring the construct Green Supply Chain Migration strategies. Finally the paper establishes the order of contribution of the five variables constituting the construct Green Supply Chain Migration strategies.
\end{abstract}

Keywords: Automobile, CFA, Green Supply Chain Performance, Green Supply Chain Practices, Green Supply Chain Migration strategies, Indian, Manufacturing Sector, Pilot Study.

\section{Introduction}

Green Supply Chain Migration strategies has been identified as one of the ten Green Supply Chain Performance measures which are impacted by five Green Supply Chain Practices [5]. Accordingly, this paper identifies the variables constituting the construct Green Supply Chain Migration strategies [5]. Green Supply Chain Migration strategies in turn is a sub-construct of the main construct Green Supply Chain Performance. Since Green Supply Chain Migration strategies has been identified as being constituted of five variables, it is of interest to know how these five variables fare in the pilot empirical study of the Indian automobile manufacturing sector by means of a questionnaire instrument [5]. It is also of interest to know the order of contribution of these five variables constituting the construct Green Supply Chain Migration strategies. The 50 automobile manufacturing plants that were surveyed during the pilot empirical study are among the ones listed in [2]. The survey methodology was used in line with the findings of [3].

\section{The Research Questions}

The six research questions identified are as follows:

Research Question 1. To have a feel of the responses of the Indian Automobile Manufacturing Sector pertaining to the five variables constituting the construct Green Supply Chain Migration strategies.

Research Question 2. To know the reliability of the questionnaire instrument for measuring the construct Green Supply Chain Migration strategies.

Research Question 3. To know the reliability of the questionnaire instrument for measuring the five variables constituting the construct Green Supply Chain Migration strategies.

Research Question 4. How are the five variables constituting the construct Green Supply Chain Migration strategies correlated?

Research Question 5. How many factors are retained by the five variables constituting the construct Green Supply Chain Migration strategies?

Research Question 6. What is the order of contribution of the five variables constituting the construct Green Supply Chain Migration strategies? 


\section{The Construct Green Supply Chain Migration Strategies And Its Five Component Variables Used In The Study}

There are five variables that constitute the construct Green Supply Chain Migration strategies. They are depicted in Table 1 in their abbreviated form.

Table 1. The five variables constituting the construct Green Supply Chain Migration Strategies

\begin{tabular}{|c|c|c|c|c|c|}
\hline $\begin{array}{c}\text { The five variables constituting the construct Green } \\
\text { Supply Chain Migration strategies }\end{array}$ & GSCMIG1 & GSCMIG2 & GSCMIG3 & GSCMIG4 & GSCMIG5 \\
\hline
\end{tabular}

\section{The Descriptive Statistics Of The Scaled Data On Green Supply Chain Migration Strategies}

A five point balanced Likert scale was used to scale the data from respondents on whom a questionnaire was administered. The respondents were employees of Indian automobile manufacturing firms and /or their plants as mentioned in [2]. The data collected revealed the following descriptive statistics of the five variables constituting the construct Green Supply Chain Migration strategies.

Table 2. Descriptive Statistics of the data scaled by the questionnaire on Green Supply Chain Migration strategies

\begin{tabular}{|c|c|c|c|c|c|c|}
\hline \multicolumn{7}{|c|}{ Simple Statistics } \\
\hline Variable & $\mathrm{N}$ & Mean & Std Dev & Sum & Minimum & Maximum \\
\hline GSCMIG1 & 50 & 3.92000 & 1.22624 & 196.00000 & 1.00000 & 5.00000 \\
\hline GSCMIG2 & 50 & 3.88000 & 1.20611 & 194.00000 & 1.00000 & 5.00000 \\
\hline GSCMIG3 & 50 & 4.00000 & 1.16058 & 200.00000 & 1.00000 & 5.00000 \\
\hline GSCMIG4 & 50 & 3.98000 & 1.09712 & 199.00000 & 1.00000 & 5.00000 \\
\hline GSCMIG5 & 50 & 4.34000 & 1.25536 & 217.00000 & 1.00000 & 5.00000 \\
\hline
\end{tabular}

\section{The Reliability Of The Instrument For The Variables And Construct Used}

The reliability of the questionnaire instrument developed by [5] for the construct Green Supply Chain Migration strategies is shown in the Table 3 as 0.979889 which is considered to be excellent [4].

Table 3. Reliability by Cronbach's Coefficient Alpha for the construct Green Supply Chain Migration Strategies

\begin{tabular}{|c|c|}
\hline \multicolumn{2}{|c|}{ Cronbach Coefficient Alpha } \\
\hline Variables & Alpha \\
\hline Raw & 0.978998 \\
\hline Standardized & 0.979889 \\
\hline
\end{tabular}

The reliability of the questionnaire for the five variables that constitute the construct Green Supply Chain Migration strategies is shown in Table 4. All the five variables in Table 4 have a reliability greater than 0.9 which is considered as excellent internal consistency reliability [4].

Table 4. Reliability of the individual five variables constituting the construct Green Supply Chain Migration strategies

\begin{tabular}{|c|c|c|c|c|}
\hline \multicolumn{5}{|c|}{ Cronbach Coefficient Alpha with Deleted Variable } \\
\hline \multirow{2}{*}{$\begin{array}{c}\text { Deleted } \\
\text { Variable }\end{array}$} & $\begin{array}{c}\text { Raw Variables } \\
\text { Correlation } \\
\text { with Total }\end{array}$ & Alpha & $\begin{array}{c}\text { Correlation } \\
\text { with Total }\end{array}$ & Alpha \\
\hline GSCMIG1 & 0.962560 & 0.970146 & 0.964024 & 0.971434 \\
\hline GSCMIG2 & 0.952392 & 0.971685 & 0.953262 & 0.973052 \\
\hline GSCMIG3 & 0.932777 & 0.974693 & 0.932050 & 0.976223 \\
\hline GSCMIG4 & 0.969320 & 0.970164 & 0.969589 & 0.970594 \\
\hline GSCMIG5 & 0.883455 & 0.982732 & 0.883900 & 0.983328 \\
\hline
\end{tabular}

\section{The Pearson's Correlation Coefficient Among The Variables Used In The Study}

The Pearson's Correlation coefficient between different pairs of variables that constitute the construct Green Supply Chain Migration strategies is shown in Table 5. Since the values of correlation coefficient are positive and between 0.8 and 0.9 in some cases and above 0.9 in others, it indicates that all the five variables that make up the construct Green Supply Chain Migration strategies are oriented towards the goal of Green Supply Chain Migration strategies in a unidirectional manner. This is also an indicator of internal consistency reliability. 
Table 5. Pearson's Correlation coefficient among the five variables of Green Supply Chain Migration Strategies

\begin{tabular}{|c|c|c|c|c|c|}
\hline \multicolumn{6}{|c|}{$\begin{array}{c}\text { Pearson Correlation Coefficients, } \mathrm{N}=50 \\
\text { Prob }>|\mathrm{r}| \text { under } \mathrm{H} 0: \mathrm{Rho}=0\end{array}$} \\
\hline & GSCMIG1 & GSCMIG2 & GSCMIG3 & GSCMIG4 & GSCMIG5 \\
\hline GSCMIG1 & 1.00000 & $\begin{array}{c}0.98689 \\
<.0001\end{array}$ & $\begin{array}{c}0.88909 \\
<.0001\end{array}$ & $\begin{array}{c}0.98481 \\
<.0001\end{array}$ & $\begin{array}{c}0.83999 \\
<.0001\end{array}$ \\
\hline GSCMIG2 & $\begin{array}{c}0.98689 \\
<.0001 \\
\end{array}$ & 1.00000 & $\begin{array}{c}0.87477 \\
<.0001 \\
\end{array}$ & $\begin{array}{c}0.96979 \\
<.0001 \\
\end{array}$ & $\begin{array}{c}0.83622 \\
<.0001 \\
\end{array}$ \\
\hline GSCMIG3 & $\begin{array}{c}0.88909 \\
<.0001 \\
\end{array}$ & $\begin{array}{c}0.87477 \\
<.0001 \\
\end{array}$ & 1.00000 & $\begin{array}{c}0.91359 \\
<.0001 \\
\end{array}$ & $\begin{array}{c}0.92450 \\
<.0001\end{array}$ \\
\hline GSCMIG4 & $\begin{array}{c}0.98481 \\
<.0001\end{array}$ & $\begin{array}{c}0.96979 \\
<.0001\end{array}$ & $\begin{array}{c}0.91359 \\
<.0001\end{array}$ & 1.00000 & $\begin{array}{c}0.84965 \\
<.0001\end{array}$ \\
\hline GSCMIG5 & $\begin{array}{c}0.83999 \\
<.0001\end{array}$ & $\begin{array}{c}0.83622 \\
<.0001\end{array}$ & $\begin{array}{c}0.92450 \\
<.0001\end{array}$ & $\begin{array}{l}0.84965 \\
<.0001\end{array}$ & 1.00000 \\
\hline
\end{tabular}

\section{Factor Analysis}

Using statistical analysis software called SAS 9.2, Confirmatory Factor Analysis (CFA) was conducted on the construct Green Supply Chain Migration strategies which consist of five variables. Principal Component's method was used as the initial factor method. Accordingly the Eigenvalues were obtained as shown in the Table 6.

Table 6. Eigen values obtained by using Principal Components Method as the initial factor method.

\begin{tabular}{|c|c|c|c|c|}
\hline \multicolumn{5}{|c|}{ Eigenvalues of the Correlation Matrix: Total $=11$ Average $=1$} \\
\hline & Eigenvalue & Difference & Proportion & Cumulative \\
\hline 1 & 4.62986914 & 4.36428159 & 0.9260 & 0.9260 \\
\hline 2 & 0.26558755 & 0.19217380 & 0.0531 & 0.9791 \\
\hline 3 & 0.07341375 & 0.05069023 & 0.0147 & 0.9938 \\
\hline 4 & 0.02272352 & 0.01431749 & 0.0045 & 0.9983 \\
\hline 5 & 0.00840603 & & 0.0017 & 1.0000 \\
\hline
\end{tabular}

An Eigen value indicate the relative importance of each factor in accounting for the particular set of variables being analysed. From Table 6 it is clear that the first factor can explain 4.62986914 variables. No other factor in Table 6 can explain at least one variable. Hence only the first factor will be retained by MINEIGEN criterion as the only factor as shown by the factor pattern of Table 7. The variance explained by the only factor is 4.6298691 .

Table7. Factor pattern obtained for the single factor retained by MINEIGEN criterion

\begin{tabular}{|c|c|}
\hline \multicolumn{2}{|c|}{ Factor Pattern } \\
\hline & Factor1 \\
\hline GSCMIG1 & 0.97817 \\
\hline GSCMIG2 & 0.97126 \\
\hline GSCMIG3 & 0.95587 \\
\hline GSCMIG4 & 0.98158 \\
\hline GSCMIG5 & 0.92332 \\
\hline
\end{tabular}

The final communality estimates for the five variables constituting the construct Green Supply Chain Migration strategies are shown in Table 8.

Table 8. The final communality estimates for Green Supply Chain Migration Strategies

\begin{tabular}{|r|r|r|r|r|}
\hline \multicolumn{5}{|c|}{ Final Communality Estimates: Total $=4.629869$} \\
\hline GSCMIG1 & GSCMIG2 & GSCMIG3 & GSCMIG4 & GSCMIG5 \\
\hline 0.95681642 & 0.94334401 & 0.91368686 & 0.96349424 & 0.85252762 \\
\hline
\end{tabular}

Communality estimates are indicative of how much of each variable is accounted for by the underlying factors taken together. A high value of communality means that not much of the variable is left over after whatever the factors represent is taken into consideration. In short the communality estimates are indicative of the relative contribution of each of the variables in the construct. Accordingly Figure 1 shows in the descending order, the relative contribution of each of the five variables of the construct Green Supply Chain Migration strategies as follows: GSCMIG4, GSCMIG1, GSCMIG2, GSCMIG3 and GSCMIG5. 


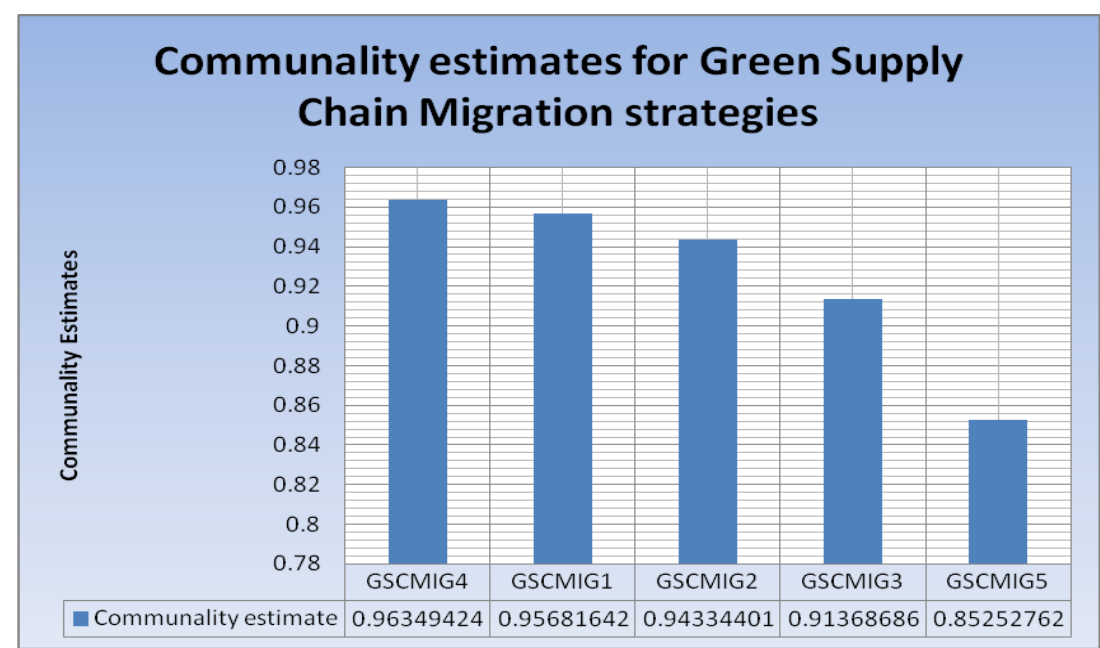

Figure 1. Contribution of the five components of Green Supply Chain Migration Strategies in descending order.

VIII. Conclusion

The aim of this paper was to study the contribution of the five variables constituting the construct Green Supply Chain Migration strategies in Green Supply Chain Performance measurement. It was found that all the five variables in the study were strongly correlated with each of the other variables meaning that all the five variables involved are strongly oriented towards Green Supply Chain Migration strategies. The reliability of the construct Green Supply Chain Migration Strategies was 0.979889 which is considered to be an excellent internal consistency reliability. Also the reliability of the five variables constituting the construct Green Supply Chain Migration Strategies was between 0.8 and 0.9 in some cases and above 0.9 in the other cases which means that the questionnaire is reliable to measure each of the variables and also the construct Green Supply Chain Migration strategies as a whole. Also the results of Confirmatory Factor Analysis reveal that one factor accounting for 4.6298691 variables is retained. Finally the contribution of the five variables of the construct Green Supply Chain Migration strategies in descending order of their contribution in the construct is as follows: GSCMIG4, GSCMIG1, GSCMIG2, GSCMIG3 and GSCMIG5.

\section{Acknowledgements}

I express my heartfelt thanks to Dr. Abdul Razak Honnutagi for permitting me to go ahead with my research work from NITIE, Mumbai though our institute was at its formative stage. Also I acknowledge the patience and support of my wife Yasmin Mohd. Asif Gandhi for bearing with me during my long research hours for years. I also express my thanks for the support and love of my loving children Mohd. Hasan Gandhi and Binish Gandhi. I express my heartfelt thanks to my parents Mr. Indravadan Chimanlal Gandhi and Mrs. Sarmista Indravadan Gandhi for encouraging me and motivating me to complete my research work. I dedicate all my success to them. Special thanks to my guide Dr. Sanjay Sharma from NITIE, Mumbai.

\section{References}

[1] Emmett, S. and Sood, V., Green Supply Chains - An Action Manifesto. John Wiles \& Sons, 2010, 201-213.

[2] Gandhi, M.A., A Review of the Indian Automobile Manufacturing Sector, IOSR Journal of Business and Management, 19(3), Ver II, 2017, 9-15

[3] Gandhi, M.A. and Sharma, S., A Review of Research Methodologies Linking Green Supply Chain Practices and Green Supply Chain Performance, International Journal of Supply Chain Management, 3(4), 2014.

[4] George, D., and Mallery, M. Using SPSS for Windows step by step: a simple guide and reference. 2003

[5] Sharma, S., and Gandhi, M.A., Exploring correlations in components of green supply chain practices and green supply chain performance, Competitiveness Review, 26(3), 2016, 332-368. 